ENCYCLOPÉDIE Encyclopédie berbère

BERBERE

$36 \mid 2013$

36| Oryx - Ozoutae

\title{
Ours : Période antique, sources littéraires
}

Jehan Desanges

\section{CpenEdition}

Journals

Édition électronique

URL : https://journals.openedition.org/encyclopedieberbere/2868

DOI : 10.4000/encyclopedieberbere.2868

ISSN : 2262-7197

\section{Éditeur}

Peeters Publishers

\section{Édition imprimée}

Date de publication : 2 juin 2013

Pagination : 5983-5984

ISBN : 978-2-7584-0194-0

ISSN : 1015-7344

\section{Référence électronique}

Jehan Desanges, «Ours : Période antique, sources littéraires », Encyclopédie berbère [En ligne], 36 |

2013, document 053, mis en ligne le 12 mars 2021, consulté le 17 février 2022. URL : http://

journals.openedition.org/encyclopedieberbere/2868; DOI : https://doi.org/10.4000/

encyclopedieberbere. 2868

Ce document a été généré automatiquement le 17 février 2022.

(c) Tous droits réservés 


\title{
Ours : Période antique, sources littéraires
}

\author{
Jehan Desanges
}

1 La présence de l'ours (grec ồ $\varkappa \tau o \varsigma$, latin ursus) en Afrique Mineure dans l'Antiquité est attestée par de nombreux témoignages littéraires. Il est par ailleurs souvent représenté sur des mosaïques d'époque romaine dans cette aire géographique, et notamment sur celles qui sont conservées au musée du Bardo, dans la banlieue de Tunis, mais ces représentations n'ont pas la même valeur probante : il faudrait en effet pouvoir établir qu'il ne s'agit pas de thèmes importés sans rapport avec les réalités locales. C'est pourquoi, par un scrupule qu'on jugera peut-être un peu excessif, nous n'en ferons pas état.

2 Hérodote (IV, 191) est le premier à signaler l'ours, au V $\mathrm{V}^{\mathrm{e}}$ siècle avant notre ère, à l'ouest du fleuve Triton, c'est-à-dire en gros à l'ouest du golfe de Gabès, dans la partie boisée et montagneuse de l'Afrique du Nord. Virgile évoque par deux fois (Én. V, 37 ; VIII, 368) la peau d'une ourse libyenne. Ce sont aussi des peaux d'ours, de lions ou de panthères qui servaient, selon Strabon (XVII, 3, 7), d'enveloppe protectrice de jour et de couverture quand ils dormaient, aux fantassins maurousiens* vivant dans le Maroc actuel, tout comme à leurs semblables masaesyles* de l'Oranie et de l'Algérois: elles les protégeaient des morsures d'animaux sauvages (Id., XVII, 3, 11, in fine). Seule voix discordante : Pline l'Ancien déclare par deux fois (VIII, 131 et 228) qu'il n'y a pas d'ours en Afrique et que c'est même un fait reconnu (\$131). Mais en VIII, 228, il affirme aussi, après Aristote ( $H$. A. VIII, 28, 606a), l'absence en Afrique du sanglier, du cerf et de la « chèvre sauvage » (qu'il confond avec le chevreuil), ce qui est faux (Gsell, p. 114-119). Son assertion est donc livresque et suspecte, bien qu'il ait séjourné en Afrique sous Néron ou Vespasien. Au reste, il est obligé de mettre en doute (\$131) le témoignage officiel des Annales, rédigées par les magistrats en charge pour rendre compte des événements de l'année : selon celles-ci, le 17 septembre 61 avant notre ère, onze jours avant le triomphe de Pompée sur l'Orient, un édile donna dans le cirque à Rome un spectacle de cent ours «numidiques » qu'affrontèrent des chasseurs éthiopiens. On ne voit pas pourquoi la provenance de ces ours aurait été inventée : il s'agissait sans doute 
d'un cadeau de la dynastie massyle régnant en Numidie, très liée à Pompée qui avait jadis chassé dans le royaume (Plutarque, Pompée, XII, 5), et les chasseurs " éthiopiens ", ou «faces-brûlées", acteurs du spectacle, provenaient vraisemblablement des territoires situés au sud de la Numidie, en bordure du Sahara, cf. EB, A71. Aethiopes. Sources antiques.

En fait, d'autres témoignages viennent démentir Pline. Martial $(\mathrm{I}, 104,5)$ évoque le spectacle à Rome des ours libyques qui obéissent au commandement du frein, et Juvénal (IV, 99-100), celui des ours numides dans l'arène d'Albe. Le fait même qu'on appelle ces ours tantôt libyques et tantôt numides montre qu'il ne s'agit pas d'une métaphore figée pour désigner une autre espèce animale et qu'on n'est pas dans le cas des "boeufs de Lucanie » que furent les éléphants de guerre aux yeux des paysans italiens qui les découvraient. Dion Cassius (LIII, 27, 6) semble considérer comme des bêtes sauvages de Libye trois cents ours qui furent mis à mort lors de jeux prétoriens donnés à Rome en 25 avant notre ère, ainsi que $($ LIX, 7,3$)$ quatre cents autres voués à une fin semblable par Caligula en 37 de notre ère. Solin $(26,3)$, abréviateur le plus souvent servile de Pline l'Ancien au III ${ }^{\mathrm{e}}$ siècle de notre ère, ne partage cependant pas les réserves de celui-ci et nous dit même que les ours numidiques l'emportent sur les autres par leur naturel rageur et l'épaisseur de leur toison. Les passions de saints africains mentionnent aussi des ours, ainsi à Carthage, en 203, dans la célèbre Passion de Perpétue et Félicité (\$19); en 304, dans l'amphithéâtre de Thuburbo, un ours féroce, maintenu à jeun, épargna des vierges chrétiennes (Passiones tres martyrum Africanarum, 7) ; Augustin (Contra Academicos, I, 2 ; cf. Sermons, XXXII, 20) évoque les ours exhibés à l'occasion de jeux offerts par son riche protecteur Romanianus dans sa modeste ville natale de Thagaste (Souk Ahras). Il est invraisemblable que tous ces ours soient venus d'outre-mer. Ajoutons enfin qu'il est question d'ours et des bestiaires qui les affrontaient sur des tablettes magiques d'exécration trouvées à Carthage (Audollent, $\left.\mathrm{n}^{\circ} 247,250,252,253\right)$.

Il apparaît donc qu'il serait tout à fait hypercritique de privilégier les assertions bien isolées de Pline l'Ancien et de nier l'existence de l'ours dans la partie occidentale de l'Afrique du Nord antique. Mais, comme l'éléphant, l'ours a été chassé avec acharnement et capturé pour agrémenter les spectacles du cirque. Cette pratique, jointe aux progrès de l'agriculture et de l'urbanisation ainsi qu'à l'expansion démographique de l'Afrique romaine jusqu'à la fin du $\mathrm{IV}^{\mathrm{e}}$ siècle, a pu restreindre dès cette époque le nombre de ces grands animaux. Comme récrivait déjà au début du III ${ }^{\mathrm{e}}$ siècle, en s'en félicitant, Tertullien de Carthage (De anima, XXX, 3), qui était bien loin d'être acquis à l'écologie et n'aurait sans doute pas soutenu chaudement la cause de la protection de l'ours : " les sillons ont dompté les forêts, les troupeaux ont mis en fuite les bêtes sauvages » (Siluas arua domuerunt, feras pecora fugauerunt).

\section{BIBLIOGRAPHIE}

AMAT J., Passion de Perpétue et Félicité, suivie des Actes, Sources chrétiennes nº 417, Paris, 1996. 
AODOLLENT A., Defixionum tabellae, Paris, 1904.

CAMPS G., « Le bestiaire libyque d'Hérodote », BACTH, n. s. 20-21, Afrique du Nord, 1984-1985,

p. 17-27 (plus particulièrement p. 18).

GSELL St., Histoire ancienne de l'Afrique du Nord, I, Paris, 1914, p. 115.

«Passiones tres martyrum Africanorum SS. Maximae, Donatillae et Secundae, S. Typasii ueterani et S. Fabii vexilliferi ", Analecta Bollandiana, IX, 1890, p. 107-134.

INDEX

Mots-clés : Antiquité, Zoologie 